DESIGNING FOR STRENGTH 
By the same author

A Background to Engineering Design

Systematic Errors in Engineering Experiments 


\section{Designing for Strength}

Principles and Practical Aspects of Stress Analysis for Engineers and Students

\section{Peter Polak}

Department of Mechanical Engineering,

University of Sheffield 
(C) Peter Polak 1982

Softcover reprint of the hardcover 1st edition 1982

All rights reserved. No part of this publication may be reproduced or transmitted, in any form or by any means, without permission.

First published 1982 by

THE MACMILLAN PRESS LTD

London and Basingstoke

Companies and representatives

throughout the world

Typeset in 10/12 Times by

Oxprint Ltd, Oxford

ISBN 978-0-333-32676-3 ISBN 978-1-349-16975-7 (eBook)

DOI 10.1007/978-1-349-16975-7

The paperback edition of the book is sold subject to the condition that it shall not, by way of trade or otherwise, be lent, resold, hired out, or otherwise circulated without the publisher's prior consent in any form of binding or cover other than that in which it is published and without a similar condition including this condition being imposed on the subsequent purchaser. 


\section{CONTENTS}

Preface

Acknowledgements $\quad$ x

Notation $\quad$ xi

Summary of Useful Formulae xiii

1 Introduction 1

2 Stresses and Strains 5

2.1 Tension and Compression 5

$\begin{array}{lll}2.2 & \text { Bending } & 7\end{array}$

2.3 Buckling 18

2.4 Shear 27

2.5 The Connection between Tension and Shear 38

2.6 Combined Tensile and Shear Loads 39

2.7 Multiple Shear $\quad 42$

3 Some Material Properties 48

3.1 The Main Low Speed Tests and Properties 48

3.2 Theory of Tensile Properties 50

3.3 Local Yielding and Residual Stresses 52

3.4 Fatigue Loading and Fatigue Tests 53

3.5 Toughness and Brittleness 62

3.6 Short Notes on Temperature Problems 65

3.7 Corrosion and Stress 68

4 Stress Concentrations $\quad 71$

4.1 Shouldered Shafts $\quad 72$

4.2 Grooved Shafts 74

4.3 Bolt-heads 78

$\begin{array}{lll}4.4 & \text { Screw Threads } & 79\end{array}$

4.5 Holes in Bars 81

4.6 Shafts with Holes, Keyways or Splines 84 
4.7 Flat Bars with Enlarged Portions; Shouldered Tubes 85

$\begin{array}{lll}4.8 & \text { Some Stress-reducing Design Features } & 87\end{array}$

5 Structures in Tension and Compression - Frame Structures 89

5.1 Simple Wall Brackets $\quad 89$

5.2 More General Frames $\quad 91$

5.3 Methods of Sections 95

5.4 Theoretical Optimum Structures $\quad 97$

5.5 Simple Redundant Structures 101

6 More Advanced Tension Problems 108

6.1 Gravity Effect 108

6.2 Centrifugal Effects 108

6.3 Curved Members with Transverse Forces 110

6.4 Stresses and Strains in Discs 114

6.5 Temperature Stresses 122

6.6 Bolted Assemblies under Load Changes 125

6.7 The Catenary and Similar Problems 128

7 Beam Problems 139

$\begin{array}{lll}7.1 & \text { Basics } & 139\end{array}$

7.2 Moment Area and Energy Methods 141

$\begin{array}{lll}7.3 & \text { Standard Cases } & 142\end{array}$

7.4 Some Applications $\quad 145$

7.5 Statically Indeterminate Beams 150

7.6 Optimum Support Points 153

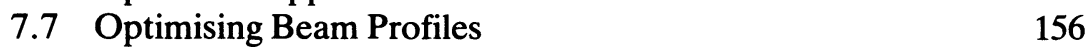

7.8 Curved Frames 158

7.9 Rectangular Frames 161

7.10 Bending of Curved Members Including Flange Distortion $\quad 169$

7.11 Maxwell's Reciprocity Theorem 173

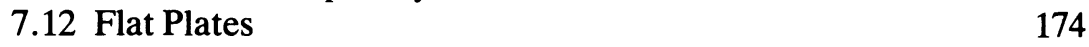

7.13 Effect of Holes and Bosses on Strength and Stiffness

7.14 Plastic Hinges $\quad 180$

7.15 Centre of Flexure; Shear Centre 181

7.16 Springs with Bending Action 182

8 Some Aspects of Structural Steelwork Design 189

8.1 Elastic Lateral Buckling of Beams 189

8.2 Beam Flange Problems 191

8.3 Beam Web Design Problems 196

8.4 Interaction Problems 202 
$\begin{array}{lll}8.5 & \text { Joints and Junctions } & 204\end{array}$

8.6 Joints in Tubular Structures $\quad 209$

8.7 Bolted or Riveted Connections 210

9 Pressure Vessels 218

$\begin{array}{lll}9.1 \text { Introduction } & 218\end{array}$

9.2 Wall Thickness Requirements against Internal Pressure 220

9.3 External Pressure 223

$\begin{array}{lll}9.4 & \text { Nozzles } & 224\end{array}$

9.5 Flanges 230

9.6 Fatigue Assessment of Pressure Vessels 237

9.7 Brittle Fracture Assessment 240

$\begin{array}{lll}9.8 & \text { Vessel Supports } & 240\end{array}$

9.9 Pipes and Bends 244

$\begin{array}{ll}9.10 \text { Corrugated Bellows } & 250\end{array}$

10 Short Case Studies 255

10.1 The Comet Mk 1255

10.2 Turbine Shaft Failure 255

10.3 Diesel Engine Connecting Rod 257

10.4 Rotor Pin Stresses $\quad 258$

10.5 Mine Hoist Brake Failure 261

Appendix 264

A.1 Time and Speed Effect in Fatigue Testing 264

A.2 Size Effect in Fatigue 265

A.3 Loading Sequence and Stress Ratio in Fatigue 266

A.4 Some Aspects of Toughness Testing 268

A.5 Residual Stress due to Local Yielding 272

A.6 Discs and Thick Cylinders 273

A.7 Buckling of Compression Springs;
Surge Frequency Derivation

A.8 Beams with Resilient Supports 278

A.9 Solid Curved Bars 281

A.10 The Connection between the Elastic Constants E, G and $\nu \quad 284$

A.11 Construction of Mohr's Circle for Stress Given $\sigma_{x}, \sigma_{y}$ and $\tau_{x y} 285$

A.12 Funicular Polygon for Bending Moments 286

A.13 A Short Note of Typical Material Properties 287

$\begin{array}{ll}\text { A.14 Selected Structural Sections } & 289\end{array}$

$\begin{array}{ll}\text { A.15 Thin-wall Buckling } & 290\end{array}$

$\begin{array}{ll}\text { References } & 304\end{array}$

$\begin{array}{lr}\text { Index } & 309\end{array}$ 


\section{PREFACE}

This book is intended to cover strength calculations for general design purposes at a standard suitable for most three-year engineering degree courses, but omitting academic fracture mechanics, soil mechanics, reinforced concrete, advanced civil engineering, aircraft structures and plasticity. The basic plan is to explain the main stress forms first, leading on to a critical examination of material tests and properties. Then before proceeding to applications it is deemed necessary to present a substantial summary of stress concentration data. The applications aspect is treated first in fairly fundamental terms, followed by aspects and procedures specific to structural steelwork and pressure vessels. It concludes with case studies, further discussion of earlier items, some useful tables, derivations and graphical methods, etc. Within some of the chapters the natural break-points between elementary and advanced work have been indicated. Most readers will wish to take a quick look at the advanced sections but defer detailed study of the arguments until a second work-through.

A large amount of important recent material and little-known older material is included in suitably condensed form, with references to readily available publications, as may be seen from the list. These references have all been closely studied by the author. An unusual feature is the inclusion of buckling as a major stress form. Most books leave this to the end as if it were a minor academic refinement instead of a major design criterion. Designers should welcome the frequent reminders to consider the highest equivalent stress, out-of-plane shear and Poisson contraction.

Sections containing particularly recent or rarely seen material of practical relevance are 2.4.2, 3.4.3, 4.4, 4.5, 5.4, 6.4.2, and 7.6 (three supports), 7.8 to 7.10 particularly flange bending effects, 7.12, 8.3.4, 8.5, 9.3, 9.8 and 9.9.

In engineering science we often find that full-size work, analogue or smallscale experiments and calculations all give different results. Sometimes these can be tracked down to one of the following

(1) genuine size effect, notably the difficulty of scaling object size and material grain size in the same ratio without altering some properties;

(2) Poisson's ratio differences, notably in photoelastic three-dimensional work;

(3) loading differences between specimens in testing machines and details within real structures; 
(4) communication problems - many experiments and their logging are carried out by assistants rather than by the authors of the papers; this leaves room for misunderstandings, oversights and insufficient precautions against systematic errors;

(5) computing problems - many papers give the very basic equations and the conclusions without describing the routes between them; in computation it is often necessary to simplify the route and it is not always obvious what physical features have been concealed thereby.

It is always difficult to steer a middle course between long tedious explanations and too much brevity. In case the book is used without the benefit of teaching staff, the earlier parts are explained fairly fully. In the advanced sections it is assumed that the reader has also advanced in knowledge and familiarity with the material, so the explanations are more condensed in the interests of smoothness. The basic examples are set out in some detail to help in avoiding misunderstandings; advanced examples are treated more concisely, as befits more advanced students.

Bearing in mind that this is a degree-standard text with much new material, it is hoped that the presentation adopted will please most of the people most of the time.

\section{ACKNOWLEDGEMENTS}

The author wishes to thank the University of Sheffield for the granting of one term's study leave, photographic and secretarial assistance and library services. The help of the library of the Institution of Mechanical Engineers is also gratefully acknowledged.

The following have kindly granted permission to reproduce material: the editors of Engineering, Engineering Materials and Design and Aircraft Engineering; also the following publishers: The Institution of Mechanical Engineers, Chapman \& Hall, Plenum Press, The British Standards Institution, Verlag Stahleisen (Dusseldorf), The British Constructional Steelwork Association and CONSTRADO.

Special thanks are due to Alan Chidgey for a number of improvements in chapter 9, consisting of additional points, rectification of misleading impressions, etc. 


\section{NOTATION}

$A$ cross-sectional area usually with subscript; axial length of flanges

$a \quad$ general-purpose length notation

$B$ breadth

$b \quad$ general-purpose length notation

C speed of stress waves as specified locally; torsional stress constant (torque $/ \tau$ ); spring constant $D / d$

$D, d \quad$ diameters

$E \quad$ Young's modulus

$E^{\prime} \quad$ wide-beam modulus $E /\left(1-\nu^{2}\right)$

$e \quad$ extension, eccentricity of loading

$F \quad$ force

$f \quad$ frequency (spring surge) $; f_{\mathrm{f}}=$ flexibility factor; $f_{\mathrm{s}}=$ stress factor (pipe bends)

$G \quad$ modulus of rigidity

$g$ gravitational acceleration

$H$ height of beam section

$h \quad$ general height; sag of catenary

I second moment of area

$J$ polar moment

$K \quad$ torsional stiffness constant for non-circular sections

$k$ radius of gyration, usually $k_{y}$ or the lowest (oblique in angle sections), $k=\sqrt{ }(I / A)$, also stiffners or thermal conductivity

$L \quad$ length, span of beam

$M \quad$ bending moment; $M_{\mathrm{f}}=$ fixing moment; $\boldsymbol{M}_{\mathrm{c}}=$ central moment; $M_{\mathrm{j}}=$ junction moment (corner moment)

$m$ coefficient used in flange theory

$N \quad$ number of active turns in helical spring

$n \quad$ end-fixing constant in Euler strut calculation

$P \quad$ force, usually vertical point load; $P_{\mathrm{ce}}=$ critical elastic buckling load

$p \quad$ fluid pressure; contact pressure; force per unit contact area

$Q \quad$ force, usually horizontal

$R \quad$ resilience, $\mathrm{d} x / \mathrm{d} P$; reaction force; radius of curvature or large radius

$r \quad$ radius

$S, s \quad$ distance along a curve

$T$ torque; tension in catenary; thickness (larger of two thicknesses)

$t \quad$ thickness; temperature 
$U \quad$ strain energy

$V \quad$ volume

$w \quad$ load per unit length

$x, y \quad$ cartesian coordinates, defined locally if necessary

$Z \quad$ section modulus, $I / y_{\max }$

$z \quad$ defined locally as required

$\alpha \quad$ coefficient of linear thermal expansion $\mathrm{mm} / \mathrm{mm}{ }^{\circ} \mathrm{C}$

$\Delta \quad$ deflection

$\epsilon, e \quad$ strain

$\theta \quad$ angle

$\nu \quad$ Poisson's ratio

$\rho$ density

$\sigma \quad$ direct stress, usually tensile if positive (except when discussing buckling)

$\sigma_{\mathrm{y}} \quad$ yield stress except in sections 2.5, 2.6 and A.11 (defined locally as stress in $y$ direction)

$\sigma_{\mathrm{ce}}$ mean compressive stress when member is at critical elastic buckling load

$\sigma_{\mathrm{d}} \quad$ design stress (pressure vessels, chapter 9)

$\sigma_{\mathrm{r}} \quad$ radial stress

$\tau \quad$ shear stress; $\tau_{\mathrm{ce}}=$ critical elastic stress for shear buckling of beam web

$\phi \quad$ shear angle, general angle if defined locally

$\psi \quad$ angle

$\omega \quad$ angular velocity 


\section{SUMMARY OF USEFUL FORMULAE}

Some are accurate, others approximate for quick-checking work.

$I=$ second moment of area (moment of inertia) as used in bending equations

$I / y$, sometimes called $Z=$ section modulus in bending (elastic) when $\sigma=$ $M / Z$

$J=$ polar moment as used in torsion formulae for circular shafts

$J / r=$ torsional modulus convenient for finding stess when $\tau=$ torque $\times$ $r / J$

$K, C$ are torsional constants for long non-circular bars, equivalent to $J$ and $J / r$

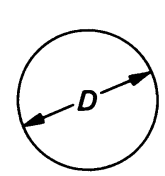

$$
\begin{array}{ll}
I=\frac{\pi D^{4}}{64} & J=\frac{\pi D^{4}}{32} \\
Z=\frac{\pi D^{3}}{32} & \frac{J}{r}=\frac{\pi D^{3}}{16}
\end{array}
$$

Solid Rod

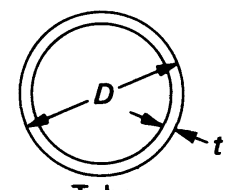

$$
\begin{array}{ll}
I \approx \frac{1}{3} D^{3} t & J \approx \frac{2}{3} D^{3} t \\
Z \approx \frac{2}{3} D^{2} t & J / r \approx 1 \frac{1}{4} D^{2} t
\end{array}
$$

Tube

$$
\begin{aligned}
& K=\frac{1}{3} B T^{3}\left(1-0.63 \frac{T}{B}+\right. \\
& \left.0.053 \frac{T^{5}}{B}\right)
\end{aligned}
$$

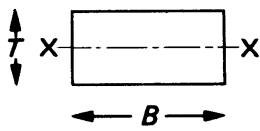

$I_{x}=\frac{B T^{3}}{12}$

$z_{x}=\frac{B T^{2}}{6}$

$C=\frac{B^{2} T^{2}}{3 B+1.8 T}$

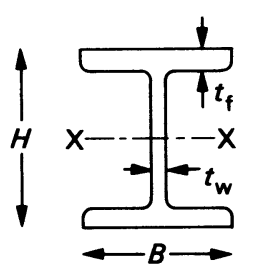

$$
I_{x} \approx 0.55 B t H^{2}
$$$$
K \approx \frac{2}{3} B t^{3} \text { if } t_{w} \ll B
$$

$Z_{x} \approx 1.1 \mathrm{BtH}$

$C \approx 2 / 3 B t^{2}$

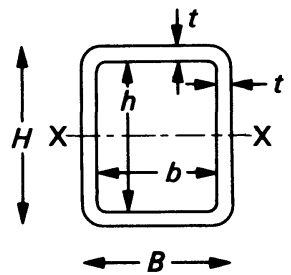

$I_{x}=\frac{B H^{3}-b h^{3}}{12}$

$$
K \approx \frac{2 B^{2} H^{2} t}{B+H+7 t}
$$

$Z \approx 1.2 \mathrm{BtH}$

$C \approx \frac{8 B^{2} H^{2} t}{(B+H)^{2}}$

Figure P.1 
SELECTED BENDING MOMENT FORMULAE FROM CHAPTER 7

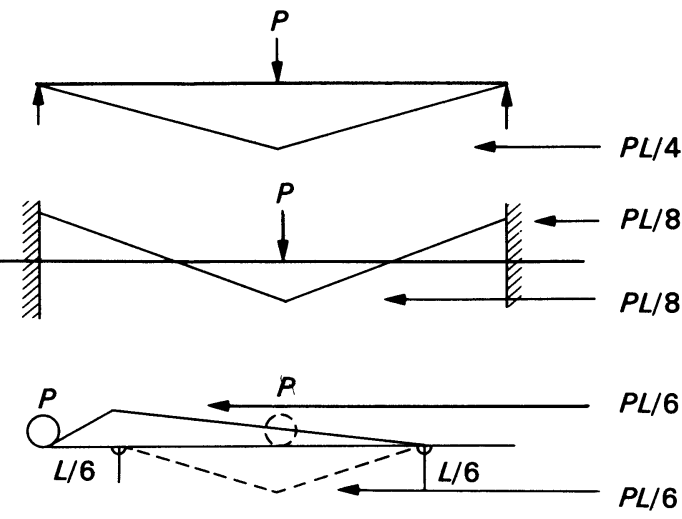

$W$
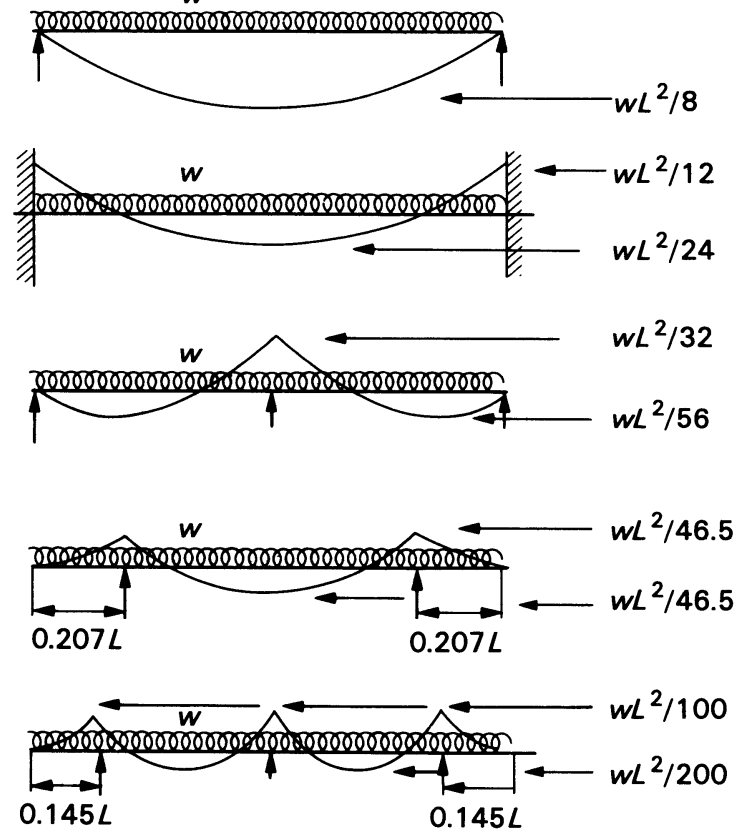

Figure P.2

$$
0.145 L
$$

$0.145 L$
$L=$ full length of beam

Fixed ends (rare) or continuous beam with similar loads each side

Optimum support spacing for travelling load

Fixed ends (rare) or continuous beam with similar loads each side

Supports on common level when loaded

A favourable support spacing

A favourable support spacing if supports are level when loaded 